\title{
Role of Ultrasound in Diagnosis of Fetus Acardius Acephalus in Multiple Pregnancies
}

\author{
Ruby Yadav ${ }^{1}$ Nishi Choudhary ${ }^{2}$ \\ ${ }^{1}$ Department of Obstretics and Gynaecology, Lady Hardinge \\ Medical College, New Delhi, Delhi, India \\ 2Department of Obstretics and Gynaecology, Safdarjung Medical \\ Hospital, New Delhi, Delhi, India
}

\begin{abstract}
Address for correspondence Ruby Yadav, MBBS, DNB (Obgy), Department of Obstretics and Gynaecology, Lady Hardinge Medical College, New Delhi 110001, Delhi, India (e-mail: drrubyyadav@gmail.com).
\end{abstract}

Int J Recent Surg Med Sci 2018;4:85-87
Abstract
Keywords
- fetus acardius acephalus
- multiple pregnancy
- perinatal outcomes
- ultrasound

This case report describes an acardiac fetus of the acephalus phenotype in a triplet pregnancy. The diagnosis was confirmed at 13 weeks. In the absence of signs of heart failure in the co-fetus, the pregnancy was managed conservatively. The pregnancy was complicated by preterm labor and the fetuses were delivered at $23+4$ weeks. Also, the perinatal outcomes of triplet pregnancies complicated by an acardiac fetus, where the median gestational age at delivery is 23 to 24 weeks, are summarized, and the possible therapeutic interventions have been discussed.

\section{Introduction}

Fetus acardius is a monster that can only occur in monozygotic multiple pregnancy, approximately 1 in 35,000 births in twin pregnancies ${ }^{1-3}$ and 1 in 30 in triplet gestations. ${ }^{3}$

It is also referred to as TRAP (twin reversed arterial perfusion) sequence, wherein because of arterial-arterial and venous-venous anastomoses, ${ }^{2,3}$ the acardiac fetus thrives as a parasite by getting blood supply from the donor hydropic twin, thus being completely dependent on the normal twin as some of the blood reaching the placenta via the umbilical artery of the normal fetus passes directly into the umbilical artery of the monster. ${ }^{1,3}$

Such anastomoses lead to preferential perfusion of the parasitic twin's lower body with low-pressure hypoxemic blood coming from the normal donor twin. ${ }^{3}$ This results in a "living" thing that does not have a heart, together with varying degrees of upper body regression in the recipient twin.

Based on the degree of cephalic and truncal maldevelopment, four types are recognized:

- Acardius acephalus: The head is lacking as are the upper extremities.

- Acardius anceps: The most developed form; partly developed head with remnants of cranial bones and brain tissue. The body and extremities are also developed.

- Acardius acormus: The rarest form. A head without a body. Placenta is attached to the head directly or via an umbilical cord ending in its cervical region.
- Acardius amorphous: The least developed monster not recognizable as a human form with minimally developed visceral organs with no gross human form.

\section{Case History}

A 30-year-old primigravida was diagnosed with triplet pregnancies on ultrasound done at 13 weeks of gestation wherein two normal live fetuses and an edematous lower half of the third fetus without any cardiac activity were detected. Subsequent ultrasound done at 18 weeks of gestation revealed two normal live fetuses and an abnormal third fetus with absent head and grossly edematous and thickened soft tissue around the trunk.

No significant medical or family history and no history of consanguinity were present.

At 23 weeks 4 days of gestation, the patient presented with the complaint of watery discharge per vaginam and spontaneously expelled three fetuses the same evening with the following details ( - Fig. 1):

- Fetus A: Living male, covered with thick dark brown skin. No obvious abnormalities, weighing $550 \mathrm{~g}$.

- Fetus B: Dead female, acardiac acephalus, with no cephalic structures, weighing 250 g. Covered with thick, dark brown skin, soft and edematous and possessed one almost fully formed upper limb on left side, one upper limb bud on right side and both lower limbs fully formed, with bilateral congenital talipes equinovarus (CTEV) ( - Fig. 2 ).
License terms

()(1) $\Theta \circledast$ 


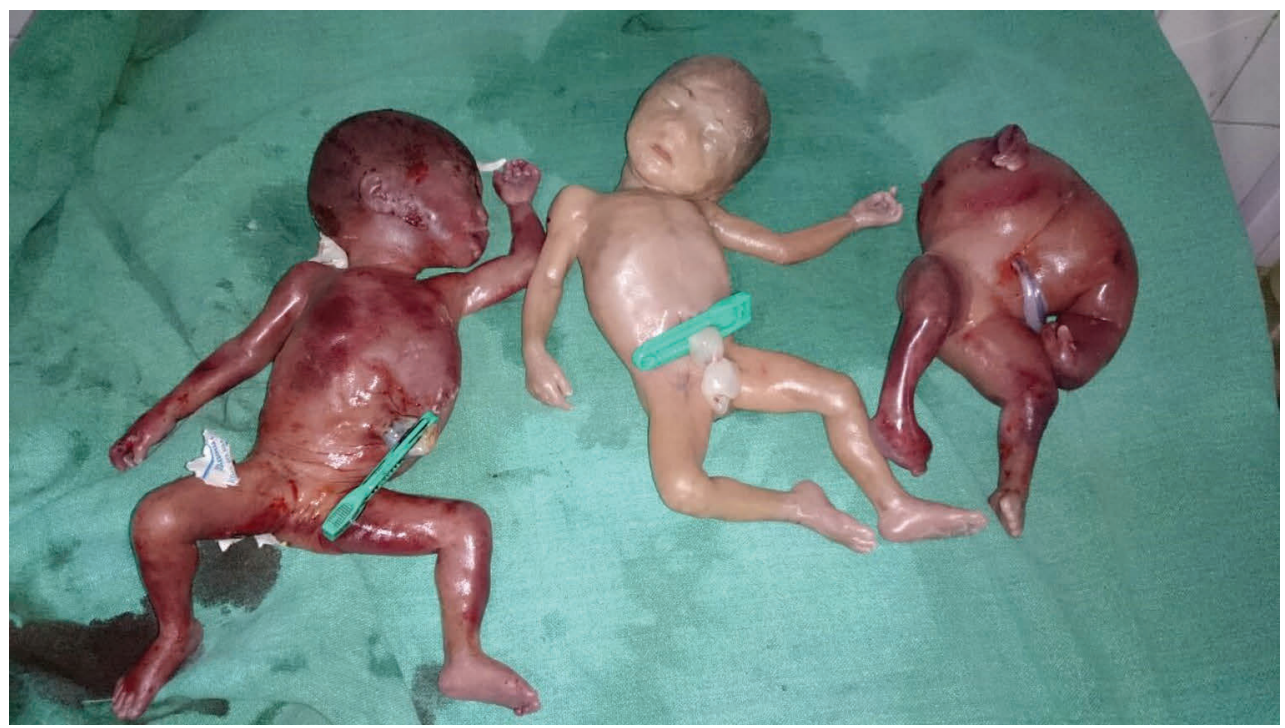

Fig. 1 Two normal fetuses and one acardiac acephalus, expelled at 23 weeks of gestation.

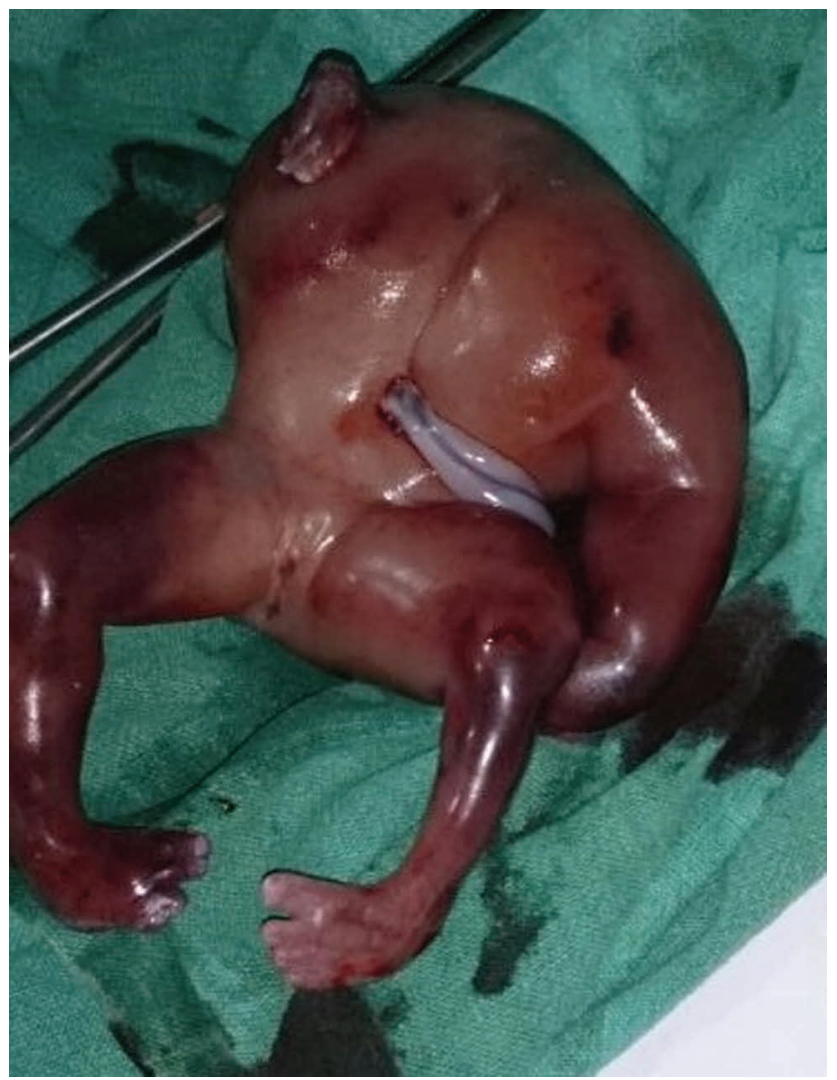

Fig. 2 Dead female acardiac acephalus, with no cephalic structures.

- Fetus C: Living female with no obvious abnormalities, weighing $410 \mathrm{~g}$.

Placenta was monochorionic, diamniotic, weighing $350 \mathrm{~g}$.

\section{Discussion}

\section{Diagnosis}

Transvaginal Doppler sonography can detect acardiac fetuses at an earlier gestational age and with greater accuracy by detecting inversion of vascular flow in the recipient acardiac fetus. ${ }^{3}$ Final diagnosis of the acardiac fetus can be made as early as 9 weeks.

Diagnosis error can occur when acardiac fetus is adherent to the placenta. In that case, diagnosis will be ascertained only at birth. When acardiac structure is initially interpreted as intrauterine fetal death, the diagnosis may be amended at following ultrasound examination, when one notices that cellular mass has increased in volume.

Therefore, as soon as the ultrasonography (USG) detects a twin pregnancy, chorionicity should be determined, and if monochorionic, Doppler should be performed to detect such a TRAP sequence. ${ }^{3}$ This improves diagnostic accuracy and ability to evaluate the extent and severity of organ compromise in pregnancies complicated by acardiac fetuses. ${ }^{3}$

At present, early diagnosis by transvaginal sonography depends on observation of the following signs:

- Monozygotic twin gestation (absence of the lambda sign)

- Biometric discordance between the twins

- Diffuse subcutaneous edema or morphologic anomalies of one of the twins, or both

- Absence of cardiac activity (although hemicardia or pseudocardiac may be present $)^{3}$

Mortality rate for the pump twin is reported between 50 and $70 \%$, and early diagnosis may allow measures to be taken that may help reduce the risk of such complications. ${ }^{4}$ Fetal echo can also be used to evaluate signs of heart failure in the pump twin.

\section{Complications}

Hydramnios is a common feature in such pregnancy due to absent amniotic fluid swallowing. ${ }^{1}$

Burden of providing circulation of two fetuses can result in cardiac hypertrophy, congestive failure, hydrops fetalis, or premature birth of normal fetus, ${ }^{1,4}$ with a mortality rate between 50 and $70 \%{ }^{4}$ 
As the umbilical cord of acardiac twin is usually hypotrophic, it is likely to be torn during manipulation resulting in death of normal fetus due to blood loss through anastomosis.

\section{Management}

Management aims at interrupting the blood flow from the pump twin to the acardiac twin without harming the normal twin. ${ }^{5}$ Follow-up is recommended every 2 weeks for ultrasound examination, fetal echocardiography, biophysical profile, Doppler ultrasound, and a calculation of the ratio of estimated acardiac/pump fetus weight.

The in utero treatment modalities that have been attempted include medical therapies, selective delivery of the acardiac twin in the second trimester followed by prolongation of pregnancy for the normal twin and umbilical cord blockage. The most promising one seems to be endoscopic ligation of the acardiac twins' umbilical cord with a success rate of 70 to $80 \%$. USG-guided thrombosis of the umbilical artery using absolute alcohol or thrombogenic coils or fibrin has been successfully attempted. In other cases, a high-energy device is used to destroy the blood vessels and surrounding tissue at the site where they enter the acardiac twin, a procedure termed radiofrequency ablation. ${ }^{5}$

\section{Conclusion}

Fetus acardius is a monster occurring in monozygotic multiple pregnancy resulting from TRAP sequence with the presence of a parasitic acardiac twin that thrives as a parasite by getting blood supply from the donor hydropic twin.

It is associated with hydramnios, cardiac hypertrophy, congestive failure, hydrops fetalis, premature birth, or mortality of normal fetus.

Diagnosis is confirmed by transvaginal Doppler USG and is managed by interrupting blood flow from the normal fetus to the acardiac fetus.

\section{Conflict of Interest}

None.

\section{References}

1 Moore TR, Gale S, Benirschke K. Perinatal outcome of forty-nine pregnancies complicated by acardiac twinning. Am J Obstet Gynecol 1990;163(3):907-912

2 Shalev E, Zalel Y, Ben-Ami M, Weiner E. First-trimester ultrasonic diagnosis of twin reversed arterial perfusion sequence. Prenat Diagn 1992;12(3):219-222

3 Bonilla-Musoles F, López A, Pardo G, et al. Sonographische Diagnose eines Holoakardius. Ultraschall Med 1987;8 (4):185-188

4 Brassard M, Fouron JC, Leduc L, Grignon A, Proulx F. Prognostic markers in twin pregnancies with an acardiac fetus. Obstet Gynecol 1999;94(3):409-414

5 Kirubamani NH. Successful pregnancy in triple with trap sequence. Indian J Sci Technol 2012;5(9):3304-3306 